\title{
BENEFícIOS DA SISTEMATIZAÇÃO DA ASSISTÊNCIA DE ENFERMAGEM PARA O PACIENTE E PARA A ENFERMAGEM
}

\section{ARTIGO DE REVISÃO}

SANTOS, Genilson Gaudêncio dos ${ }^{1}$

FILHO, José Jefferson da Silva Nascimento ${ }^{2}$

SANTOS, Genilson Gaudêncio dos. FILHO, José Jefferson da Silva Nascimento. Benefícios da sistematização da assistência de enfermagem para o paciente e para a enfermagem. Revista Científica Multidisciplinar Núcleo do Conhecimento. Ano 05, Ed. 08, Vol. 07, pp. 16-28. Agosto de 2020. ISSN: 2448-0959, Link de acesso: https://www.nucleodoconhecimento.com.br/saude/beneficios-dasistematizacao

\section{RESUMO}

A Sistematização da Assistência de Enfermagem é uma forma organizada de cuidar e alcançar qualidade na assistência oferecida. Este estudo tem como objetivos: Relatar a relevância da SAE para a Enfermagem, identificando os benefícios da mesma para a enfermagem e para o cliente. Trata-se de uma revisão de literatura. A pesquisa foi desenvolvida a partir de consulta em livros, revistas e artigos científicos disponíveis na internet e nas bases de dados; LILACS e SCIELO. Para a coleta de dados foram utilizadas as seguintes palavras-chave: SAE, cuidar e processo de enfermagem. Os dados foram agrupados e organizados para tratamento estatístico descritivo simples. $100 \%$ dos autores acreditam nos benefícios da SAE como estratégia definidora do espaço/campo de atuação do enfermeiro justificando a

\footnotetext{
${ }^{1}$ Pós-Graduado em Enfermagem do Trabalho pela Universidade Cândido Mendes UCAM; Pós-Graduado em Enfermagem de Urgência e Emergência pela Faculdade Integrada de Araguatins - FAIARA; Graduado em Enfermagem pela UNESC.

${ }^{2}$ Graduado em Medicina pela Faculdade de Medicina Nova Esperança - FAMENE.
} 
existência de tal profissional na equipe multidisciplinar. $60 \%$ afirmam que a SAE traz a consolidação da ciência de enfermagem, reconhecimento e valorização do profissional enfermeiro. $40 \%$ afirmam que organiza o cuidado/assistência de enfermagem. $100 \%$ acreditam que traz benefícios para o cliente como: assistência individualizada, organizada, humanizada, detecta diagnósticos precocemente, cuidados de enfermagem feita corretamente, reduz infecção e estadia de clientes hospitalizados. Apesar de estar já regulamentado pela resolução COFEN 358/09 e ser uma exigência do Conselho Federal de Enfermagem à SAE ainda não está sendo utilizada nem faz parte do trabalho de muitos enfermeiros e instituições de saúde do país, mas, a negligência da SAE é a principal razão da omissão, da desorganização e falta de confiança das ações de enfermagem.

Palavras-chave: SAE, cuidar, processo de enfermagem.

\section{INTRODUÇÃO}

A Enfermagem como Ciência do cuidado com o ser humano agora mais do que nunca está apta e interessada em atingir uma assistência de qualidade. A Sistematização da Assistência de Enfermagem (SAE) é uma forma organizada de cuidar e alcançar qualidade na assistência oferecida. Sendo assim o enfermeiro profissional a quem lhe é outorgado o direito de cuidar, deve fazer uso da metodologia da SAE para desenvolver da melhor maneira e aplicar na assistência seus conhecimentos técnicocientíficos em prol de alcançar qualidade e eficiência no cuidado ao cliente.

Desde a década de 80 o planejamento da assistência de enfermagem é uma imposição legal. A partir de 2002 a SAE tornou-se uma exigência legal do Conselho Federal de Enfermagem (COFEN) através da resolução n² 272/2002 revogada pela resolução COFEN 358/2009, que dispões sobre a SAE e a implantação do Processo de Enfermagem (PE) em ambientes, públicos ou privados, em que ocorre o cuidado profissional de Enfermagem, determina a SAE como uma atividade privativa do enfermeiro que tem por objetivos identificar as situações de saúde/doença e contribuir no direcionamento dos cuidados para o indivíduo e coletividade visando à promoção, prevenção e recuperação da saúde. 
Então a SAE e o Processo de Enfermagem são objeto de pesquisas, tanto na academia como nos ambientes de trabalho de saúde, com o objetivo de aperfeiçoar o saber científico dos cuidados/assistência de enfermagem, conferir atendimento individualizado e garantir a autonomia do enfermeiro (BACKES et al, 2008).

Partindo-se do conceito do que é ciência ou conhecimento científico sabemos que toda ciência é dotada de um processo sistematizado e metódico, ou seja, um arcabouço de conhecimentos em que se fundamenta sua prática.

De acordo com Lunarde Filho (1997) grande parte dos cuidados ou atendimento de enfermagem não fica registrada nem documentada de alguma maneira e isso é lamentável. De modo que esse atendimento não pode ser estatisticamente descrito. Não podendo esse atendimento ou assistência servir para a visibilidade do enfermeiro e da profissão.

Apesar de estar já regulamentado pela resolução COFEN 358/09 e ser uma exigência do Conselho Federal de Enfermagem à SAE ainda não está sendo utilizada nem faz parte do trabalho de muitos enfermeiros e instituições de saúde do país, mas, a negligência da SAE é a principal razão da omissão, da desorganização e falta de confiança das ações de enfermagem.

A escolha da realização deste trabalho que objetivou identificar os benefícios da SAE para a enfermagem e para o paciente/cliente parte do pressuposto que a enfermagem deve lançar mão da metodologia da SAE já regulamentada pela resolução COFEN 358/2009 para ser consolidada enquanto disciplina/ciência e oferecer uma assistência mais humana ao paciente/cliente.

A SAE constitui o ápice da profissão. Como disse Horta (1979) com o processo de enfermagem, hoje entendido como sendo um método de implantar na prática a SAE, a profissão atingiu a sua consolidação. Além de ser uma forma organizada/sistematizada e humana de cuidar.

O presente estudo revela que há uma escassez de obras que abordam a temática da SAE sobre a ótica dos benefícios trazidos por essa metodologia. Em relação às 
publicações em forma de artigos científicos sobre a temática da SAE podemos afirmar que foram inúmeros achados, porém, a maioria tratava das dificuldades encontradas pelos profissionais de implementarem nos serviços de saúde essa metodologia, por isso, foram excluídos deste trabalho cuja intenção foi trazer os seus benefícios.

Existe uma necessidade extrema por literaturas que venham abordar os benefícios da SAE visto que essa metodologia constitui-se de uma forma positiva bilateralmente quando se considera a profissão de enfermagem e a pessoa receptora do cuidado e da assistência do enfermeiro. Sobre a relevância e os benefícios da SAE 100\% dos autores, pesquisados acreditam nos benefícios da aplicação da metodologia da SAE tanto para a enfermagem quanto para o cliente.

A SAE mostra sua relevância nos seguintes aspectos: trás a consolidação da ciência de Enfermagem, autonomia, maior reconhecimento e valorização do profissional enfermeiro, oferece uma assistência individualizada e organizada, uma assistência mais humanizada, detecta diagnósticos precocemente, assegura que os cuidados de enfermagem sejam feitos corretamente, reduz as infecções em clientes hospitalizados e reduz a duração/estadia do cliente no hospital.

\section{METODOLOGIA}

Trata-se de uma revisão de literatura, ou seja, de pesquisas existentes que foram compiladas em um único documento construindo assim uma pesquisa bibliográfica, que de acordo com Gil (2002), se desenvolve a partir do material teórico, documentos, artigos científicos etc. Já elaborados, que servem como base de orientação ao trabalho que está sendo desenvolvido, pois dá ao pesquisador uma maior abrangência do tema pesquisado, possibilitando, a validação do estudo.

Para Rossi Júnior (1990), a pesquisa bibliográfica é aquela que se desenvolve a partir da tentativa de resolução do problema (hipótese), através das referências teóricas encontradas em livros, revistas e literatura afim. 
A pesquisa foi desenvolvida a partir de consulta em livros, revistas e artigos científicos disponíveis na internet e nas bases de dados; LILACS e SCIELO, utilizando-se das palavras-chave: SAE, cuidar e processo de enfermagem.

A pesquisa seguiu os seguintes passos: coletânea do material para revisão da literatura; realização de leitura do material pertinente; seleção do material pertinente ao tema; confecção do trabalho; resultados e discussão.

Após a realização da pesquisa, os mesmos foram interpretados e analisados, sendo agrupados e organizados para tratamento estatístico descritivo simples, e foram expostos em forma de texto, gráfico e tabela.

\section{RESULTADOS E DISCUSSÃO}

Os resultados foram interpretados e discutidos a partir das informações extraídas dos trabalhos selecionados.

Gráfico 1 - Fontes virtuais das publicações dos artigos científicos sobre a sistematização da assistência de enfermagem - (SAE)

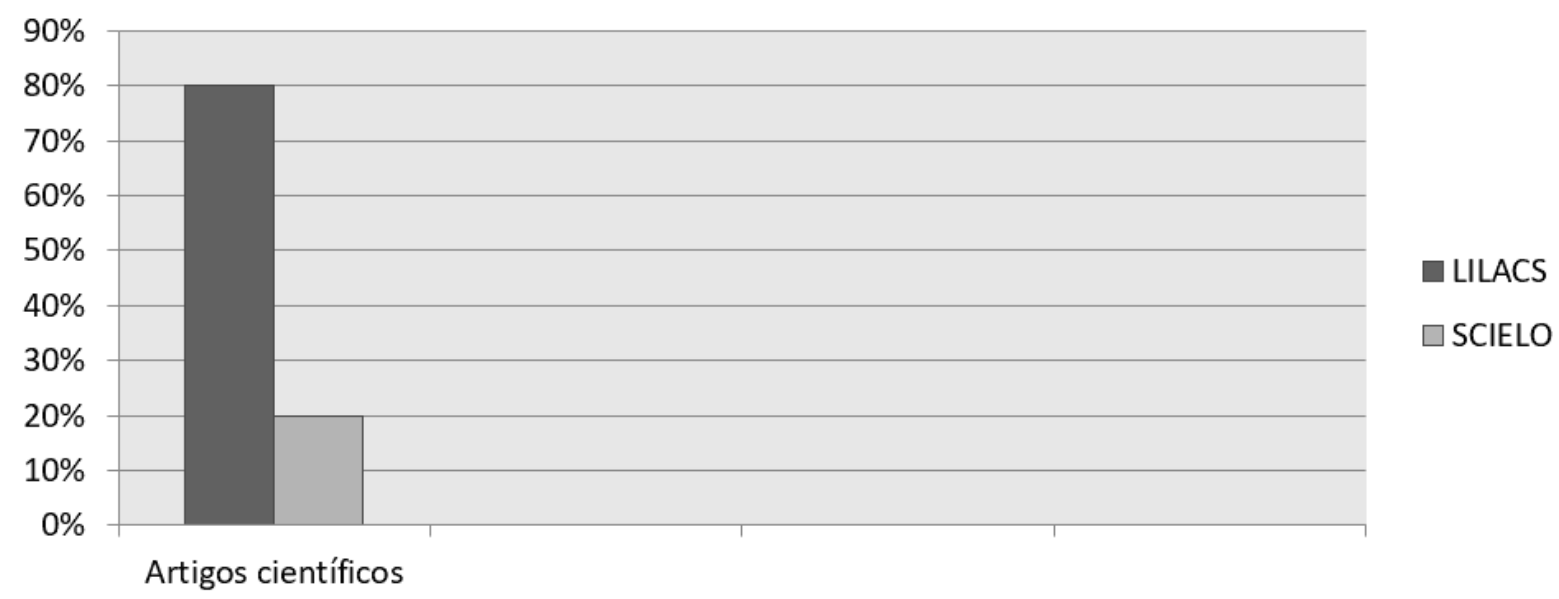

Fonte. Artigo: Benefícios da Sistematização da Assistência de Enfermagem para o Paciente e para a Enfermagem. Ano: 2020.

O Gráfico 1 mostra as fontes virtuais das publicações dos artigos científicos relacionados à SAE. Foram encontrados e/ou separados para o estudo 15 artigos 
científicos nas bases de dados LILACS e SCIELO. A maior parte destes foi selecionada na base de dados SCIELO, perfazendo um total de 12 artigos que corresponde a $80 \%$ do total pesquisado. $\mathrm{Na}$ base de dados LILACS, foram selecionados 03 artigos que corresponde a $20 \%$ do total de artigos pesquisados.

Tabela 1 - Tipos de periódicos das publicações relacionadas a conceitos sobre SAE e processo de enfermagem.

\begin{tabular}{|l|l|l|}
\hline PERIÓDICOS & No. PERIÓDICOS & (\%) \\
\hline Livros & 09 & $34,6 \%$ \\
\hline Dissertação de Mestrado & 01 & $3,85 \%$ \\
\hline TCC de Graduação & 01 & $3,85 \%$ \\
\hline Revista Latino-am. De Enfermagem & 02 & $7,7 \%$ \\
\hline Revista de Enfermagem do Centro Oeste Mineiro & 01 & $3,85 \%$ \\
\hline Revista Educação Meio Ambiente e Saúde & 01 & $3,85 \%$ \\
\hline Congresso Brasileiro de Enfermagem & 01 & $3,85 \%$ \\
\hline Revista Cogitare Enfermagem & 01 & $3,85 \%$ \\
\hline Revista Ciência Cuidado e Saúde & 01 & $3,85 \%$ \\
\hline Revista Texto Contexto Enfermagem & 02 & $7,7 \%$ \\
\hline Revista Enfermagem Atual & 01 & $3,85 \%$ \\
\hline Revista Brasileira de Enfermagem & 05 & $19,2 \%$ \\
\hline TOTAL & $\mathbf{2 6}$ & $\mathbf{1 0 0 \%}$ \\
\hline
\end{tabular}

Fonte. Artigo: Benefícios da Sistematização da Assistência de Enfermagem para o Paciente e para a Enfermagem. Ano: 2020.

A Tabela 1 mostra os tipos de periódicos das publicações pesquisadas relacionadas a conceitos sobre SAE e PE que foram selecionadas para o estudo. Foram selecionadas e separadas para o estudo 26 literaturas entre elas: livros, dissertação de mestrado, TCC de graduação e artigos científicos.

A maior parte das literaturas utilizadas no estudo foi encontrada na forma de artigos científicos em diversas revistas que perfazem $57,7 \%$ do total das literaturas analisadas 
e pesquisadas. Foi utilizada no estudo uma dissertação de Mestrado correspondendo a 3,85\%. Um TCC de graduação correspondendo a 3,85\% da amostra de trabalhos acadêmicos analisados.

Sendo assim o avanço nas literaturas publicadas em relação a SAE retomam mais aos artigos científicos, visto que foram minoria os TCC de graduação. Os respectivos índices podem talvez refletir o desinteresse dos acadêmicos pelo referido tema ou até mesmo a falta de conhecimento e embasamento sobre a temática objeto de estudo desse trabalho.

A falta de domínio do assunto SAE dos estudantes da academia é a principal razão pela escassez de obras envolvendo a temática da SAE mas isso seria assunto de uma outra abordagem/estudo.

Gráfico 2 - Benefícios da SAE para a enfermagem. Resultados sobre os benefícios da SAE para a enfermagem.

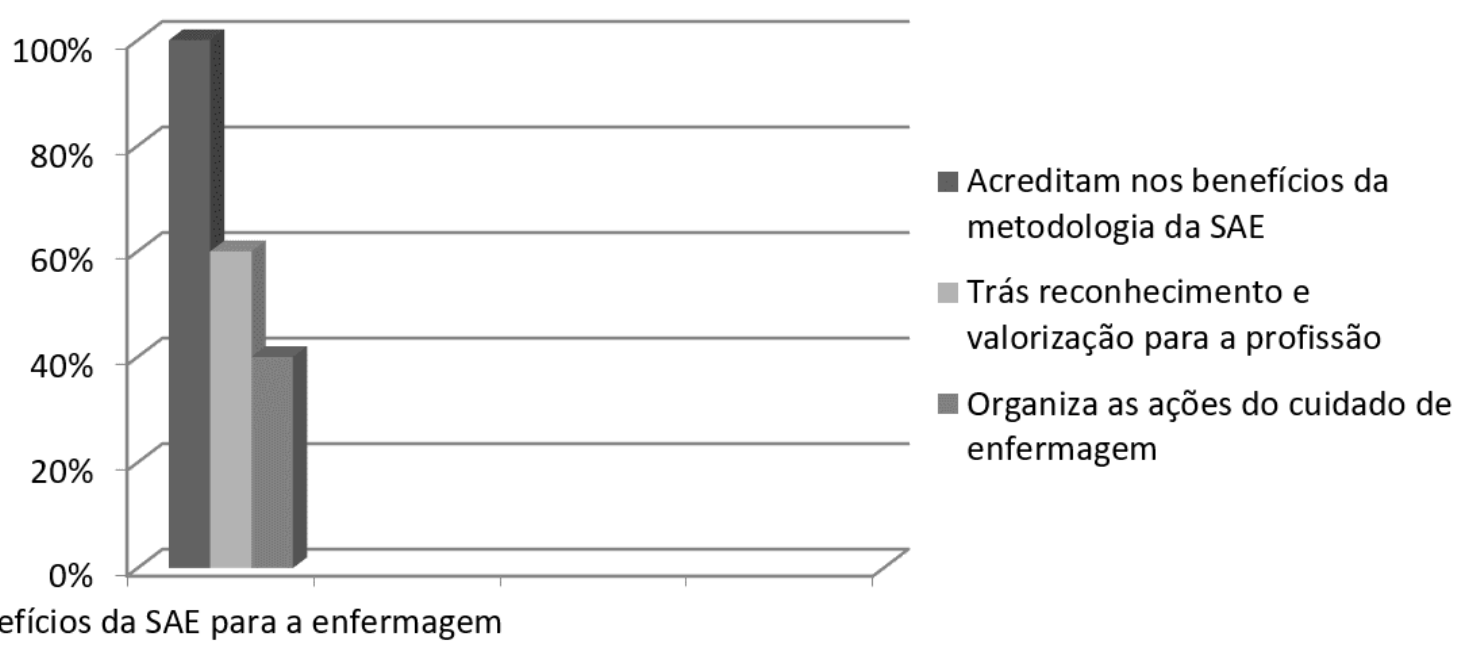

Fonte. Artigo: Benefícios da Sistematização da Assistência de Enfermagem para o Paciente e para a Enfermagem. Ano: 2020.

O Gráfico 2 mostra os resultados referentes aos trabalhos acadêmicos sobre os benefícios da SAE para a Enfermagem. Sobre a relevância da SAE para a enfermagem, $100 \%$ dos autores acreditam nos benefícios da metodologia. A exemplo de Hermida (2004) quando afirma que a enfermagem deve privilegiar suas ações 
específico-próprias junto ao cliente e atuar como parceira dos demais profissionais, não apenas como suporte de ações médicas e administrativo-burocráticas, mas compartilhando seus saberes no atendimento às necessidades do paciente. Para Grando (2005) a utilização de um sistema de cuidados que especifique tanto quantitativamente quanto qualitativamente a função do enfermeiro, serve para justificar a existência de tal profissional nos serviços de saúde.

A SAE demostrou-se eficaz em todos os aspectos que envolvem a profissão de Enfermagem, pois, $60 \%$ dos artigos analisados afirmam que a SAE traz benefícios para a profissão como:

- Consolidação da ciência de enfermagem

- Autonomia

- Maior reconhecimento do profissional enfermeiro

- Valorização do profissional enfermeiro

- Segurança para o enfermeiro e para o paciente/cliente

Como disse Horta (1979) com o PE, hoje entendido como sendo um método de implantar na prática a SAE, a profissão atingiu sua consolidação. Concorda-se com Lunardi Filho (1997) quando afirma que a prática de enfermagem não sistematizada desvaloriza a profissão, colaborando para a sua estagnação. Tannure e Gonçalves (2008) diz que a autonomia na profissão de Enfermagem só será adquirida quando toda a classe começar a utilizar a metodologia científica apresentada pela SAE, de conformidade com suas ações - ou seja, quando estiver em prática a aplicação da sistemática do processo de enfermagem. $40 \%$ dos autores afirmam que a SAE organiza as ações do cuidado de enfermagem. A exemplo de Dell'Acqua e Miyadahira (2002) quando diz que a SAE é uma forma de organizar a assistência. O mesmo afirmou Castilho et al (2009) é uma dinâmica das ações sistematizadas e inter relacionadas, que viabiliza a organização da assistência de enfermagem. 
Gráfico 3 - Benefícios da SAE para o cliente. Resultados sobre os benefícios da SAE para o cliente.

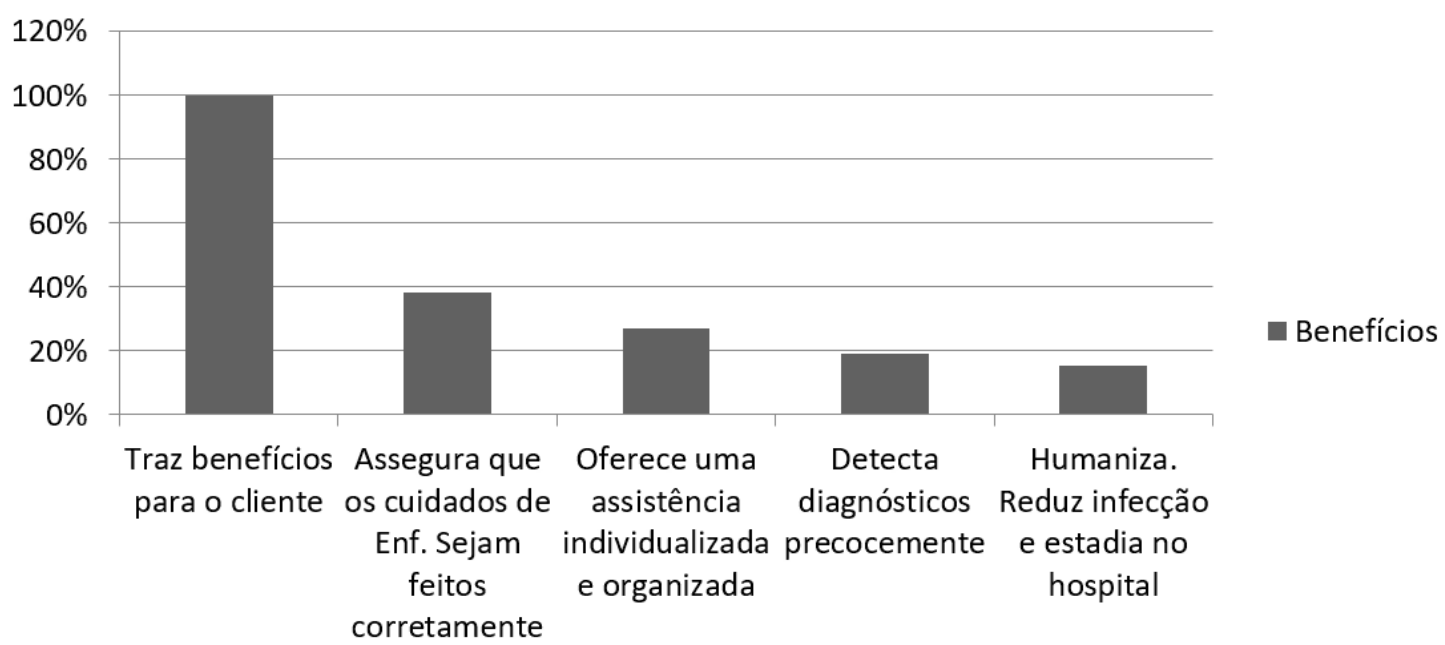

Fonte. Artigo: Benefícios da Sistematização da Assistência de Enfermagem para o Paciente e para a Enfermagem. Ano: 2020.

O Gráfico 3 mostra os resultados referentes aos benefícios da SAE para o Cliente. $100 \%$ dos autores acreditam que a SAE trás benefícios para o cliente. $38,4 \%$ asseguram que com o uso da metodologia da SAE os cuidados de enfermagem são feitos corretamente, como disse, Alfafo-Lefevre (2000) o método contido no Processo de Enfermagem (PE) utilizado pela SAE utiliza-se de formulário detalhado e minucioso que auxilia na comunicação e é capaz de prevenir iatrogenias e omissões.

Compreendemos que esses documentos produzidos pela SAE podem servir de consulta posterior para quaisquer auditorias no sentido de conferir segurança ao paciente/cliente. E podem também servir de base para estudos posteriores em enfermagem.

O mesmo afirmou Santos (2009) concordando com Alfaro-Lefevre quando disse que com a SAE é possível assegurar que os cuidados de enfermagem sejam feitos corretamente. 
26,9\% dos autores afirmam que a SAE oferece uma assistência individualizada e organizada a exemplo de Dell'Acqua e Miyadahira (200) quando diz que a SAE é um método para organização e prestação do cuidado na área, ou designar à forma de organizar a assistência. 19,2\% dizem que a SAE é capaz de detectar diagnósticos precocemente. $15,5 \%$ afirmam que a metodologia da SAE reduz as infecções em pacientes/clientes hospitalizados, a duração/estadia do paciente cliente no hospital, oferece uma assistência mais humanizada a exemplo de Santos (2009) pode-se afirmar reduzindo as infecções e a duração da estadia dos clientes nas instituições de saúde.

Castilho et al (2009) afirma que a metodologia representa uma abordagem de enfermagem ética e humanizada, dirigida à resolução de problemas, atendendo as necessidades de cuidado de saúde e de enfermagem de uma pessoa.

Então a SAE constitui-se uma metodologia de trabalho benéfica que aumenta a qualidade da assistência de enfermagem para o cliente trazendo inúmeros benefícios para o mesmo como foi citado acima e em consonância com o Gráfico 3.

\section{CONSIDERAÇÕES FINAIS}

Há uma escassez de obras que abordem a temática da SAE sobre a ótica dos benefícios trazidos por essa metodologia. Em relação às publicações na forma de artigos científicos sobre a temática da SAE podemos afirmar que foram inúmeros achados, porem, a maioria tratava das dificuldades encontradas pelos profissionais de implantarem nos serviços essa metodologia, por isso, foram excluídos deste trabalho cuja intenção foi trazer os seus benefícios.

Existe uma necessidade extrema por literaturas que venham abordar os benefícios da SAE visto que essa metodologia constitui-se de uma forma positiva bilateralmente quando se considera a profissão (enfermagem) e a pessoa receptora do cuidado/assistência (paciente). 
Sobre a relevância da SAE $100 \%$ dos pesquisadores acreditam nos benefícios da metodologia assistencial tanto para a enfermagem quanto para o cliente. A SAE mostra sua relevância nos seguintes aspectos: Trás a consolidação da ciência de enfermagem, autonomia, maior reconhecimento e valorização do profissional enfermeiro, oferece uma assistência individualizada e organizada, uma assistência humanizada, detecta diagnósticos precocemente, assegura que os cuidados de enfermagem sejam feitos corretamente, reduz as infecções em clientes hospitalizados e reduz a duração/estadia do cliente no hospital.

É muito importante que a enfermagem seja a resolução dos problemas de saúde do cliente, que dê prioridade as suas ações específicas próprias do seu campo de conhecimento atuando no diagnóstico de enfermagem.

Mas para isso é necessário que a SAE seja implantada para que dentro dos critérios científicos que ela dispõe o enfermeiro possa conhecer os diagnósticos das enfermidades acometidas pelos clientes podendo deliberar com autonomia sobre 0 cuidado e assistência de cada indivíduo (paciente) sobre sua responsabilidade.

É bem verdade que com a aplicação da SAE, o enfermeiro é capaz de identificar as necessidades humanas básicas do cliente, visualizando-o de forma holística e assim, estabelecer por meio do julgamento clínico as necessidades a serem priorizadas.

Através da SAE pode-se oferecer uma melhor assistência visto que essa organiza o cuidado e ainda mais ela delimita o campo de atuação do enfermeiro podendo este deliberar sobre a prescrição dos cuidados e tomar parte nas tomadas de decisões em meio a equipe multidisciplinar.

A enfermagem é a profissão que mais caracteriza o cuidar, a SAE é a própria oferta ao paciente desse cuidado sistematizado e organizado com embasamento científico e metódico, permitir que os cuidados sejam delegados por outros profissionais fere e compromete a assistência da profissão. Os profissionais futuros devem desenvolver o cuidado, mas, não um cuidado aleatório e sem metas, um cuidado sistematizado e organizado. 
Apesar da adoção de métodos e critérios que norteiam a orientação dos profissionais de enfermagem quanto à implantação e o uso da metodologia da SAE, esta poderá ser utilizada de inúmeras formas e executada sob diferentes perspectivas, visando sempre a qualidade das ações de enfermagem e a eficiência da assistência prestada.

A SAE é sem dúvida uma forma organizada de cuidar ao mesmo passo que organiza também o serviço da equipe de enfermagem sob gerenciamento do enfermeiro, dá direcionamento às ações, especificidade, cientificidade e ainda é um instrumento de avaliação do trabalho da enfermagem. A organização e o direcionamento das ações de enfermagem se tornam características marcantes da SAE, que desde 2002 é uma exigência legal de acordo com a Resolução COFEN 272/2002. Revogada pela resolução COFEN 358/2009.

A metodologia da SAE vem realmente definindo quem é o enfermeiro, quem é o técnico de enfermagem e suas atribuições bem como os demais profissionais da equipe multidisciplinar.

Sem a aplicação da metodologia da SAE, não podemos ter respaldo científico quantitativo e qualitativo de uma assistência profissional prestada ao paciente/cliente inviabilizando assim tal assistência ou descaracterizando-a como profissão e continuaremos a vivenciar um caos na enfermagem. Sem a metodologia da SAE teremos sempre uma enfermagem desarticulada: o Enfermeiro sem realizar o que é de sua competência, ou seja, a Prescrição de Enfermagem (prescrição dos cuidados) que se o enfermeiro não a faz está descaracterizando a própria profissão como ciência/disciplina provedora do cuidado. E o técnico de enfermagem de enfermagem fundamentando suas ações e prática em prescrições médicas e não de enfermagem, em fim teremos uma enfermagem sempre como suporte de ações médicas e/ou administrativo-burocráticas dos serviços, resumindo as anotações de enfermagem em sucintas descrições de um plantão de trabalho.

A implantação de uma metodologia de trabalho embasada cientificamente possibilita a sistematização do cuidado que consiste em utilizar uma metodologia para a realização de um trabalho organizado e consequentemente eficaz. E o resultado disto 
é sem dúvida a consolidação da profissão e visibilidade das ações ou assistência prestada pelo enfermeiro.

De acordo com a realidade de cada instituição compete ao enfermeiro a criação a criação, implantação e execução da SAE. É o enfermeiro que formula ese documento impresso da melhor maneira visando sempre a qualidade das ações de enfermagem prestadas ao cliente.

A sistematização do cuidado também fornece recursos para o desenvolvimento do conhecimento técnico-científico que caracteriza a enfermagem como ciência dos seus conhecimentos próprios e específicos.

A SAE faz uso de uma visão holística e por assim ser, confere mais humanização ao receptor das suas ações, observando o paciente de forma integral e não apenas a patologia que o acomete, assegurando que os cuidados sejam articulados diretamente para a pessoa ou paciente e não mais para a doença.

O verdadeiro papel da enfermagem é o cuidar, mas, não um cuidado aleatório e sem metas, é uma forma organizada de cuidar, pois, confere um cuidado sistematizado e organizado deixando para trás a prática aleatória do cuidado, onde não é possível alcançar objetivos concretos.

\section{REFERÊNCIAS}

ALFARO-LEFEVRE, R. Aplicação do processo de enfermagem: um guia passo a passo. Tradução de Ana Maria Vasconcellos Thorell. 4. Ed. Porto Alegre: Artes Médicas Sul, 2000.

ANDRADE, J. S.; VIEIRA, M. J. Prática assistencial de enfermagem: problemas, perspectivas e necessidade de sistematização. Revista Brasileira de Enfermagem, Brasília, mai-jun; 58(3): 261-5. 2005.

BACKES, D. S.; KOERICH, M. S.; NASCIMENTO, K. C.; ERDMANN, A. L. Sistematização da Assistência de Enfermagem como Fenômeno Interativo e 
Multidimensional. Revista Latino-am Enfermagem, novembro-dezembro; 16(6). www.eerp.usp.br/rlae, 2008.

CASTILHO et al. A Implementação da Sistematização da Assistência de Enfermagem no Serviço de Saúde hospitalar do Brasil. Texto Contexto, Enferm, Florianópoles, 2009.

CONSELHO FEDERAL DE ENFERMAGEM. Resolução COFEN no 272/2002 Dispoe sobre a sistematização da assistência de enfermagem - SAE, nas Instituições de Saúde Brasileiras. Rio de Janeiro, 27 de agosto de 2002.

Resolução COFEN no 358/2009: Dispõe sobre a Sistematização da Assistência de Enfermagem e a Implementação do Processo de Enfermagem em ambientes, públicos ou privados, em que ocorre o cuidado profissional de Enfermagem, e dá outras providências. Brasília (DF); 2009.

DELL'ACQUA, M. C. Q.; MIYADAHIRA, A. M. K. Ensino do processo de enfermagem nas escolas de graduação de enfermagem do Estado de São Paulo. Revista Latino Americana de Enfermagem, Ribeirão Preto, v. 10, n. 2, p. 185-191, 2002.

GIL, A. C. Como elaborar projetos de pesquisa. Como classificar as pesquisas 4 . Ed. São Paulo: Atlas, 2002. Cap. 4, p. 44.

GRANDO, S. R. Sistema de Apoio à Decisão à Taxonomia Nanda: Um protótipo para os diagnósticos de enfermagem a Pacientes com Acidente Vascular Encefálico. 2005. 104 f. Trabalho de Conclusão de Curso (Mestrado) - Pontifícia Universidade Católica do Paraná, 2005.

HERMIDA, P. M. V. Desvelando a implementação da sistematização da assistência de enfermagem. Revista Brasileira de Enfermagem, Brasília, v. 10, n. 6. 2004.

HORTA, W. A. Processo de Enfermagem. São Paulo: EPU: Ed. da Universidade de São Paulo, 1979. 
LUNARDE FILHO, W. D. A prescrição computadorizada de cuidado de enfermagem: o planejamento como forma inovadora de facilitação do cuidado individualizado e de sua continuidade. Cogitare Enferm., Curitiba, v. 2, n. 1, p. 90-95, jan. 1997.

ROSSI JR, Renato. Metodologia Científica para a Área de Saúde. São Paulo: Pancast, 1990.

SANTOS, H. E. A. M. A importância da implementação da sistematização da assistência de enfermagem (SAE) na prática profissional. 2009. $65 \mathrm{f}$. Trabalho de Conclusão de curso (Graduação) - Faculdade de Campina Grande - FAC - CG União de Ensino superior de Campina Grande - UNESC, 2009.

Enviado: Agosto, 2020.

Aprovado: Agosto, 2020. 